\title{
THE BOURNEWOOD GAP (AS AMENDED?)
}

\author{
Neil Allen ${ }^{1}$
}

Both the Mental Health Act 1983 and the Mental Capacity Act 2005 authorise the treatment and detention of the mentally ill. Their interface is often clear cut. After all, the 1983 Act formally sanctions and safeguards compulsion where it is necessary to protect patients or others. Individuals can only be detained for psychiatric, not physical, health purposes. ${ }^{2}$ And such detention can only take place in hospital. In contrast, the informality of the 2005 Act defends actions taken in the best interests of those unable to decide for themselves. Compulsory treatment and detention of those with capacity cannot be sanctioned. Nor can those lacking capacity be treated or detained for the protection of others.

In the wake of the Article 5 violations denounced in HL $v$ United Kingdom, ${ }^{3}$ to bridge the colloquial 'Bournewood gap' the Mental Health Act 2007 appended Schedules A1 and 1A to the 2005 Act. Since their coming into force in April 2009, the deprivation of liberty safeguards ('DoLS') have sought to prevent the arbitrary detention of adults in (only) hospitals ${ }^{4}$ and care homes. ${ }^{5}$ Those under 18 are not covered. ${ }^{6}$ Nor does the scheme apply to deprivations occurring in a carer's, or someone's own, home. Supported accommodation ${ }^{7}$ and conveyance to a care home or hospital also fall outside its ambit. ${ }^{8}$

Where best interests necessitate the detention in hospital of someone with mental disorder, but they lack the capacity to make the relevant decisions, either statute could be invoked. Schedule 1A therefore purports to differentiate the two regimes by describing five situations in which a person

\footnotetext{
${ }^{1}$ Barrister and Clinical Teaching Fellow, University of Manchester and Young Street Chambers, Manchester.

2 Mental Health Act 1983 s2 requires detention to be "related to or linked with mental disorder" (St George's Healthcare NHS Trust v. S [1999] Fam 26, 56 per Judge LJ); see also GJ ibid. n4 at [50]. Longer term detention requires appropriate medical treatment to be available whose purpose is to alleviate the mental disorder or to prevent its deterioration (MHA 1983 s145).

3 (2005) 40 E.H.R.R. 32. See K. Keywood. 'Detaining mentally disordered patients lacking capacity: The arbitrariness of informal detention and the common law doctrine of necessity' (2005) 13 Medical Law Review 108.

${ }^{4}$ Schedule 1A paragraphs 17 adopts the same meaning of "hospital" and "medical treatment" as set out in the Mental Health Act 1983.

${ }^{5}$ Ibid. at paragraph 178 defines 'care home' by reference to section 3 of the Care Standards Act 2000.

${ }^{6}$ See Children Act 1989 s25 (secure accommodation).

${ }^{7}$ See In the matter of BJ (Incapacitated Adult) [2009] E.W.H.C. 3310 (Fam.).

${ }^{8}$ However, a standard authorisation may take effect upon arrival; see Schedule A1 paragraph 52.
} 
will be ineligible for DoLS. Case A concerns those detained under a 'hospital treatment regime'. Case B involves those subject to, but not detained under, that regime: those on leave of absence or conditional discharge for example. Case $\mathrm{C}$ relates to patients on supervised community treatment. Case D deals with guardianship. And Case E refers to objecting mental health patients which was considered in GJ v. Foundation Trust, Primary Care Trust, Secretary of State for Health. ${ }^{10}$

Mr J was 65 and had a history of alcohol abuse. His partner's death had left him struggling to cope at home. Vascular dementia, Korsakoff's syndrome and diabetes had resulted in very poor shortterm memory, an inability to manage his insulin injections and self neglect. Two hypoglycaemic attacks had happened already. Brain injury, if not death, were also at risk. He was detained in hospital under the Mental Health Act 1983; initially for assessment, then for treatment.

After six months he was granted leave of absence to a care home from which he escaped four times. With the authority to detain under the 1983 Act having expired, the police returned Mr J to hospital. His detention was urgently authorised by the managing authority under DoLS. The supervisory body granted a standard authorisation for four weeks, followed by another lasting three months. He was undisputedly ineligible for the first; but Mr J contended he was also ineligible for the second. The Court of Protection was called upon to determine his eligibility under Schedule 1A, paragraph 2, Case E of the 2005 Act. Mr J attempted suicide prior to the hearing, resulting in his admission under the 1983 Act.

\section{The Objecting Mental Health Patient}

Case E renders ineligible those objecting mental health patients who are not subject to the hospital, community or guardianship regimes of the 1983 Act. ${ }^{11}$ It comprises of two tests: the ineligible status test $^{12}$ and the ineligible objection test. ${ }^{13}$ If both are satisfied, the person cannot be subject to DoLS. In relation to the first test, Charles J. held that someone was "within the scope" of the 1983 Act if,

\footnotetext{
${ }^{9}$ Defined as Mental Health Act 1983 sections 2, 4, 3, 35, 36, 37, 38, 44, 45A, 47, 48, 51 or another enactment which has the same effect as a hospital treatment obligation.

${ }^{10}$ [2009] E.W.H.C. 2972 (Fam.)

11 Mental Capacity Act 2005 s.16A states that ineligibility extends to both DoLS authorisations and judicial welfare orders.

12 Mental Capacity Act 2005 Schedule 1A paragraph 12.

13 Ibid. paragraph 5.
} 
in the assessor's view, they could be detained in hospital under sections 2 or $3 .^{14}$ Paragraph 12 required statutory assumptions to be made in that regard. The decision maker must assume that two medical recommendations under the 1983 Act have been given. For possible section 3 admissions, they must also assume that treatment cannot be provided under the 2005 Act. Moreover, his Lordship held, they "should also proceed on the assumption that assessment and treatment under s.2 MHA 1983 cannot be provided under the MCA". ${ }^{15}$

This first test could prove decisive: it could rule out the possibility of detention under the 1983 Act. A learning disability which is not associated with abnormally aggressive or seriously irresponsible conduct, for example, would be "within the ambit of the MCA but not of the MHA 1983". ${ }^{16}$ But the latter had "primacy" whenever it applied. Although the two forms of detention were not always mutually exclusive, it was unlawful for anyone "to proceed on the basis that they can pick and choose between the two statutory regimes as they think fit". ${ }^{17}$ In areas of doubt, they must "take all practical steps to ensure that that primacy is recognised and given effect to."

If the detention criteria of the 1983 Act were met, the decision maker must go on to determine the ineligible status test which is to be found in Schedule 1A paragraph 5. It consists of three conditions. First, the instrument authorising detention must authorise the person to be a "mental health patient". Second, the person must object either to having that status or to mental health treatment. Third, a donee or deputy must not make a valid decision to consent to the relevant objection. In the present case, the first condition was decisive.

A "mental health patient" was defined as someone accommodated in a "hospital"19 for the "purpose" of being given "medical treatment for mental disorder". ${ }^{20} \mathrm{Mr} J$ was clearly accommodated in hospital but the purpose was unclear. Charles J. held that eligibility assessors must first identify

${ }^{14}$ Ibid. n10 at [80].

15 Ibid. at [44].

16 Ibid. at [29]. This holds true for sections 3, 7, 17A, 20, 20A, 35-38, 45A, 47, 48, 51 and 72 of the Mental Health Act 1983. Note, however, that abnormal aggression or serious irresponsibility is not required for section 2 admissions.

${ }^{17}$ Ibid. at [59].

${ }^{18}$ Ibid. at [65].

${ }^{19}$ See $W$ Primary Care Trust v. TB, S Metropolitan Borough Council, C \& W Partnership NHS Foundation Trust, W Metropolitan Borough Council [2009] E.W.H.C. 1737 (Fam.) at [39]. Wood J. noted that the Liverpudlian care home which accommodated Ms B was not registered as an independent hospital; nor was it part of the National Health Service. It did not therefore amount to a "hospital".

${ }^{20}$ Mental Capacity Act 2005 Schedule 1A paragraph 16. 
the packages of physical and mental health care to be received in hospital. "Medical treatment for mental disorder" included a range of acts ancillary to the core treatment, as well as treatment for the disorder's symptoms. It also covered the physical consequences of the mental disorder, such as selfinjury or self-poisoning. But treatment for a physical disorder "unconnected to" a mental disorder would only be included if it was likely to "directly affect" the mental disorder.

The second stage was to determine whether the "purpose" of hospital detention was to provide medical treatment for the mental disorder. A distinction had to be drawn between the need for treatment arising from a physical condition, and whether the mental disorder warranted detention in hospital. ${ }^{21}$ The correct approach, his Lordship held, was to apply a "but for" test which, in general, would also determine whether they were within the scope of the 1983 Act. The eligibility assessor must ask themselves two questions. First, if there was no need for the physical package, should the person be deprived of their liberty? Second, was the need for the physical package the only effective reason why they should be deprived? If the respective answers were "no" and "yes", the purpose would not be to provide medical treatment for mental disorder.

Self neglect was a symptom or manifestation of Mr J's mental disorder. Diabetes was not. Both health care packages included the provision of care, monitoring and a safe environment. The package of physical treatment consisted of medication for diabetes which was unconnected to, and unlikely to directly affect, his mental disorder. The package of treatment for mental disorder consisted of medication if he did not object to it: compulsory treatment was not part of the package. "But for" the need for the physical package, Mr J should not have been detained in hospital to receive the psychiatric package. Hence, the only effective reason for the DoLS authorisation was the need for him to be treated for diabetes. Therefore, he was not a "mental health patient" and was eligible for DoLS. The same approach founded the conclusion that Mr J was not within the scope of the 1983 Act.

\section{The Agony of Eligibility}

The eligibility assessment attempts to achieve for detention that which section 28 of the 2005 Act proscribes for treatment: the pre-eminence of mental health over mental capacity law. But both

21 St George's Healthcare NHS Trust v. S [1998] 3 W.L.R. 936, 962. 
statutes have to cope with the concept of "medical treatment for mental disorder" which supposedly involves "no conceptual vagueness". 22 Judicial generosity has stretched its meaning beyond the "perfectly routine, sensible treatment" 23 that Parliament envisaged. Naso-gastric feeding of those with anorexia, ${ }^{24}$ personality disorder, ${ }^{25}$ or depression ${ }^{26}$ has satisfied its elastic demands. So too have long periods of seclusion, ${ }^{27}$ a structured environment, ${ }^{28}$ physical restraint and caesarean sections. ${ }^{29}$ Even treatment for merely suspected disorders of the mind suffices because to require a "state of mind of precision and sureness" beyond reasonable doubt would not be "sensible or feasible". ${ }^{30}$ Clearly, the broader its interpretation, the broader will be the reach of the 1983 Act at the expense of the 2005 Act.

The provisions of Schedule 1A also undermine the statutory principle of least restriction to which regard must otherwise be had. ${ }^{31}$ What might be described as the 'principle of primacy' requires assessors to assume that no alternative to the 1983 Act is available and that the ink is dry on the medical recommendations. Following GJ, no-one has the discretion to choose the appropriate regime, even where hospital detention could be authorised by either DoLS or section 2 of the 1983 Act. As a result, the focus is likely to shift to whether the individual objects and, if so, whether someone else's consent should sanction informal detention.

\section{THE IRONY OF ELIGIBILITY}

Because Mr J was not a "mental health patient", it rendered academic any detailed consideration of the second or third conditions of the ineligible objection test. The purpose of the second condition - that the person objects to being a mental health patient or to mental health treatment - is to treat

\footnotetext{
22 B v. Croydon Health Authority [1995] Fam. 133, 140 per Hoffmann L.J.

${ }^{23}$ Hansard HL Debs, Ser 5, Vol 426, col 1071 Feb 11982 per Lord Eldon, introducing the Mental Health Bill in the House of Lords.

${ }^{24} \operatorname{Re} \mathrm{KB}$ (Adult)(Mental Patient: Medical Treatment) (1994) 19 B.M.L.R. 144.

${ }^{25}$ B v. Croydon Health Authority [1995] 1 F.L.R. 470; R v. Collins and another, ex parte Brady (2001) 58 B.M.L.R. 173.

${ }^{26}$ Re VS (Adult: Mental Disorder) [1995] 3 Medical Law Review 292.

${ }^{27} \mathrm{R}$ (Munjaz) v. Mersey Care NHS Trust [2006] 2 A.C. 148.

28 Hutchinson Reid v. United Kingdom (2003) 37 E.H.R.R. 9.

29 Tameside and Glossop Acute Services Trust v. CH [1996] 1 F.L.R. 762.

${ }^{30}$ R (B) v. Haddock (Responsible Medical Officer) [2006] E.W.C.A. Civ. 961 at [41] per Auld L.J. See P. Bartlett, 'A matter of necessity? Enforced treatment under the Mental Health Act' (2007) 15(1) Medical Law Review 86.

${ }^{31}$ Mental Capacity Act 2005 s1(6). See also the Act's Code of Practice at paragraphs 13.10 and 13.11 in conjunction with the 1983 Act's Code of Practice at paragraphs 4.16 and 4.22. The duty to treat in the least restrictive environment also accords with the ninth of the United Nation's Principles for the Protection of Persons with Mental Illness and for the Improvement of Mental Health, together with article 8 of the Council of Europe Recommendation Rec (2004) 10.
} 
those lacking capacity as if they had capacity to consent but are refusing to do so. ${ }^{32}$ Given their incapacity, the threshold is rightly a low one: if they would object if able, they should be assumed to be objecting. ${ }^{33}$ Charles J. thus discouraged "fine distinctions between the potential reasons for the objection to treatment of different types, or to simply being in a hospital". ${ }^{44}$ What matters is whether they do or will object to what is proposed.

The impact of objections is likely to become increasingly contentious. Particular uncertainty may arise from the fact that an objection may be made even if it is not currently being voiced. Consider, for example, a person who, throughout their life, avoided medicine wherever possible. Dementia subsequently takes hold and his best interests necessitate detention and psychiatric treatment. He now lacks capacity to decide and is entirely compliant. But decision makers know that he would object to treatment if able to do so. Should his past objections preclude the use of DoLS which may be the less restrictive option? Why are the objections of care home residents treated differently to those of hospital residents $?^{35}$ What counts as an objection?

Mr J objected. ${ }^{36}$ He frequently refused medication and objected to being detained for treatment. Thus, had the purpose of his detention been to provide psychiatric treatment, DoLS would not have been an option. Would Mr L - the raison d'être for DoLS - have been eligible according to Case E? He was within the scope of the 1983 Act and not subject to its regimes. Using Charles J.'s approach, nursing care was common to both his packages of physical and psychiatric treatment. The former also included blood tests and observation, the latter sedative and mood stabilising medication, coupled with speech, mental health and occupational therapy assessments. "But for" the package of physical health care he still required hospital detention and would therefore have been a "mental health patient".

Mr L's eligibility would have depended upon whether he objected either to being a mental health patient, or to being given some or all of the mental health treatment. He was profoundly autistic and could not speak. Despite having been sedated beforehand, he arrived at Bournewood hospital very

\footnotetext{
32 Explanatory notes to the Mental Health Act 2007 at paragraph 204.

33 Deprivation of Liberty Safeguards: Code of Practice to supplement the main Mental Capacity Act 2005 Code of Practice (The Stationery Office, 2008) at paragraph 4.46.

34 Ibid. n10 at [83].

35 Ibid. n19 at [130].

${ }^{36}$ Ibid. n10 at [35].
} 
agitated, punching his temples. He never attempted to leave but remained disturbed for most of his stay on the locked unit. ${ }^{37}$ So distressed was his behaviour that sedative medication had to be administered to manage it. He also refused a CT scan and EEG.

Having regard to all the reasonably ascertainable circumstances, including his present and, if appropriate, past behaviour, wishes, views, beliefs and values, was Mr L not objecting? ${ }^{38}$ Should he not at least have been assumed to be objecting on the basis that he would have objected had he been able? If so, the stark position is that DoLS could not be used in the very situation for which they were designed. He would have been an ineligible, objecting mental health patient whose detention could only have been authorised by the 1983 Act.

\section{CONCLUSIONS}

History will judge whether Schedules A1 and 1A of the 2005 Act have managed to plug the colloquial "Bournewood gap". To some extent they take a belt and braces approach by prescribing a procedure to deprive liberty in circumstances that go beyond the facts of Bournewood. Safeguards have thus been afforded to those requiring care home detention and hospital detention for physical ill health. Both remain unaffected by Case E because they cannot be mental health patients. ${ }^{39}$ Protective detention occurring in other settings, like supported housing, have been left to the Court of Protection to sanction. ${ }^{40}$

(Un)fortunately, the complex amendments do not plug the paradigmatic case: Mr L would have been ineligible. Indeed, unpublished figures suggest that five per cent of the 3453 detention requests received by supervisory bodies in the first six months were rejected on the basis of the eligibility requirement. ${ }^{41}$ Will the "primacy" of the 1983 Act come to the rescue of these patients' right to liberty? After all, being ineligible for DoLS does not trigger an application under the 1983 Act. Whether this takes place involves "value judgments" which can be made "within a permissible range

\footnotetext{
${ }^{37}$ See the Health Service Ombudsman's report (Case No. E. 2280/98-99) at paragraphs 12, 13, and 15.

38 Not according to Charles J. ibid. n10 at [36].

${ }^{39}$ Schedule $1 \mathrm{~A}$ Cases B and D may, however, be relevant.

${ }^{40}$ Ibid. $\mathrm{n} 7$.

$4185 \%$ failed the best interests requirement. My thanks to Mr Paul Gantley at the Department of Health for kindly providing these figures. The use of DoLS has so far been much less than expected. In its first year, the Department of Health anticipated 21,000 assessments, resulting in 5250 authorisations. The Mental Health Act Commission estimated 48,000 (R v. Bournewood Community and Mental Health N.H.S. Trust, ex parte L [1999] 1 A.C. 458, 481).
} 
of reasonable opinion". ${ }^{42}$ Decision makers may disagree which risks leaving vulnerable individuals stuck between a mental capacity rock and a mental health hard place. Thomas Jefferson was right: "the boisterous sea of liberty is never without a wave". ${ }^{43}$

${ }^{42}$ Ibid. n10 at [63].

${ }^{43}$ H.A. Washington, The writings of Thomas Jefferson: being his autobiography, correspondence, reports, messages, addresses, and other writings, official and private (1854) (Taylor \& Maury, Washington DC) Vol II page 182. 